\title{
Transformação e desenvolvimento do raciocínio projetual - reflexões pedagógicas
}

\author{
Transformation and development of the design thinking - pedagogical \\ considerations
}

\author{
MEDEIROS, Ligia M.S.; DSc; UERJ \\ ligia@esdi.uerj.br \\ BROD JUNIOR, Marcos; DSc; USFM \\ brodjr74@gmail.com \\ GOMES, Luiz A.V.N; PhD; UERJ \\ luizvidalgomes@gmail.com
}

\section{Resumo}

Este estudo aborda o processo de transformação e de desenvolvimento do raciocínio projetual que ocorre ao longo da formação do estudante em Cursos Superiores de Desenho industrial/ Design. Parte-se das premissas que: (a) projetar é atividade central e característica da profissão do Desenho industrial/Design, (b) essa atividade requer formas próprias de pensar e saber, (c) tal raciocínio pode ser aprendido e refinado a partir de experiências sistemáticas que se equilibrem entre desafios intelecto-criativos e suporte instrucional. Os trabalhos de Carmel-Gilfilen e Portillo (2010) e William Perry (1968) foram a base para a observação de um grupo de estudantes em disciplina em curso de Design no Brasil, em 2017. Procurou-se aqui apresentar: (a) a revisão de estudos anteriores úteis para o estabelecimento dos instrumentos de coleta de dados e de interpretação, (b) o relato dos estudos já iniciados; (c) uma breve discussão sobre a relevância do tema para a área de conhecimento do Design.

Palavras Chave: raciocínio projetual; educação projetual; ensino de desenho industrial

\begin{abstract}
This paper deals with the process of transformation and development of the design thinking that occurs throughout the schooling of student in Industrial Design courses. It is based on the premises that: (a) project is a central and characteristic activity of the Design profession, (b) this activity requires its own ways of thinking and knowing, (c) such thinking can be learned and refined from systematic experiences that balance intellectual-creative challenges and instructional support. The works of Carmel-Gilfilen and Portillo (2010) and William Perry (1968) were the basis for the observation of a group of students in one Design course in Brazil, in 2017. It is presented here: (a) a review of previous studies useful for the establishment of data collection and interpretation tools; (b) reporting on findings already undertaken; (c) a brief discussion of the relevance of the theme to the Design knowledge area.
\end{abstract}

Keywords: design thinking; design education; design teaching 


\section{A atividade projetual e criativa requer formas próprias de pensar e saber}

Vários pesquisadores da área da educação projetual e criativa já realizaram estudos comparando o desempenho de estudantes iniciantes e experientes como tentativa de melhor compreender o desenvolvimento das habilidades relacionadas ao projetar. Essa preocupação, tão relevante para o ensino do projeto em cursos de Desenho Industrial/Design (DiD), está registrada em inúmeros artigos acadêmicos. Uma rápida busca apresenta, por exemplo: Cross, 2004; Göker, 1997; Ho, 2001; Kavakli; Gero, 2003; Stones, 2007, Davis et al, 2018. Outros autores estudaram o raciocínio projetual - por vezes denominado design thinking- sem realizar observações comparativas em termos da experiência acumulada das pessoas analisadas. Peter Rowe, por exemplo, no livro Design Thinking, observou a estrutura subjacente do raciocínio projetual de designers-arquitetos engajados na projetação de edifícios e outros aparatos urbanos, interpretando as evidências da criação que ocorre em momentos privados, solitários, íntimos. Ele definiu seu objeto de interesse como "a lógica situacional interna e os processos de tomada de decisão" característicos quando se está projetando (1987, p.1-2). Por meio de três estudos de caso, Rowe apresentou acontecimentos suficientemente variados para permitir a discussão teórica presente no livro. Literatura também pode ser encontrada sobre o tema raciocínio projetual. Nossa própria trajetória de pesquisa vem buscando traçar correlações entre a fluência na representação gráfica (ou graficacia) e o raciocínio projetual numa tentativa de encontrar indicadores ou padrões (Medeiros, 2002), e sempre percebemos, na pesquisa bibliográfica, a lacuna de estudos voltados para o desenvolvimento de inteligência e habilidades mentais entre estudantes adultos: existe uma prevalência de estudos da criança (Cox, 2001; Freeman, 1980; Kellog, 1959; Lowenfeld, 1977; Luquet, 1981; Pillar, 1996). Por esse motivo, dentre tantos trabalhos que se aproximam do nosso intento, encontramos um relato de pesquisa que se mostrou particularmente válido como referência para o atual estágio da nossa investigação: o artigo Developmental trajectories in design thinking de Carmel-Gilfilen e Portillo, publicado em 2010. Nele, o autores retomam o modelo de William G. Perry -proposto em 1968- para análise do desenvolvimento intelectual e ético de estudantes universitários. Ética, aqui, deve ser entendida à luz do significado originário do grego ethos, que significa "traço característico de um grupo, do ponto de vista social e cultural, que o diferencia de outros", e não com o sentido de "ciência que estuda a conduta humana e a moral, e a qualidade desta conduta, quando julga-se do ponto de vista do Bem e do Mal".

O modelo de Perry já havia sido mencionado por nós em (Medeiros; Naveiro, 2002) porém sem maior desdobramento à época. Uma busca preliminar na rede mundial de computadores oferece poucas páginas sobre o esquema de Perry, mas entre elas encontra-se o artigo de Helena Marchand (2008) Desenvolvimento intelectual e ético em estudantes do ensino superior, implicações pedagógicas. A revisão da fonte original -o livro Forms of Ethical and Intellectual Development in the College Years, a Scheme, de William G. Perry- permitiu-nos uma compreensão mais completa da teoria, do modelo interpretativo e seus resultados. Segundo o esquema de Perry, estudantes do ensino superior tendem a transitar de um tipo de pensamento caracterizado por dualismo radical passando para a relativização do saber ao longo do ciclo de estudos, e de um natural amadurecimento. Carmel-Gilfilen e Portillo, utilizando esse esquema, observaram estudantes iniciantes e intermediários em Curso de Design focalizando suas observações na capacidade de lidarem com limitações e critérios. Visto que as características do 
estudo de Carmel-Gilfilen e Portillo se aproximam das pretendidas no nosso sobre raciocínio projetual, o artigo Developmental trajectories in design thinking e o livro de William Perry serão aqui referências bibliográficas centrais.

William Perry iniciou sua investigação em 1953, quando o Bureau of Study Counsel da Universidade de Harvard procurava compreender as experiências de aprendizagem dos universitários ao longo dos quatro anos de estudo. Professores constatavam que estudantes respondiam de modo muito variado ao relativismo do conhecimento. Alguns se orientavam com facilidade e demonstravam senso de realização diante das facetas do aprendizado, enquanto outros manifestavam extrema dificuldade e desconforto. Com base na análise longitudinal de centenas de respostas a questionários e entrevistas, Perry formulou nove posições (não estágios) que os estudantes poderiam ocupar em relação ao conhecimento (Quadro1). O esquema foi condensado em uma representação suficientemente rigorosa e denotativa a ponto se ser passível de replicação e teste por observadores independentes. Os resultados desse esforço de representação foram: um glossário de 20 palavras às quais significados específicos foram associados; e um quadro bidimensional delineando e codificando as formas de desenvolvimento sequencial pressupostas no esquema. Para o teste de validade, Perry reuniu seis "juízes" que receberam cópia do Glossário e do Quadro, um exemplo do protocolo de entrevista, e um manual contendo texto descritivo do estudo e do sistema de avaliação. Os juízes tiveram tempo para estudar o material e a oportunidade de discuti-lo com os pesquisadores. Uma série de procedimentos foram planejados e cumpridos para validação do estudo, seu método e resultados.

Quadro 1 - O esquema de Perry para o desenvolvimento intelectual de estudantes universitários

\begin{tabular}{|lll|}
$\begin{array}{l}\text { Nove Posições } \\
\text { no Esquema de Perry }\end{array}$ & $\begin{array}{l}\text { Estudante em relação ao } \\
\text { Conhecimento }\end{array}$ & $\begin{array}{l}\text { Estudante em relação à sua } \\
\text { Aprendizagem }\end{array}$ \\
\hline 1. Dualidade básica. & $\begin{array}{l}\text { O conhecimento é certo ou } \\
\text { errado, verdadeiro ou falso; há } \\
\text { respostas absolutas. }\end{array}$ & $\begin{array}{l}\text { As “autoridades" têm as respostas. } \\
\text { O conhecimento é recebido. } \\
\text { problemas têm soluções, e o } \\
\text { estudante deseja aprende-las. }\end{array}$ \\
\hline 2. Multiplicidade pré-legítima & $\begin{array}{l}\text { O conhecimento é geralmente } \\
\text { certo ou errado. Incerteza e } \\
\text { complexidade são percebidos } \\
\text { como erros. }\end{array}$ & $\begin{array}{l}\text { “Autoridades" têm os meios de se } \\
\text { alcançar as respostas. O estudante } \\
\text { deseja aprender as respostas certas } \\
\text { e ignorar as outras. }\end{array}$ \\
\hline
\end{tabular}

3. Multiplicidade subordinada aqueles cuja solução já conhecemos e aqueles cuja solução não conhecemos ainda.

Alguns problemas são insolúveis, portanto, qualquer resposta pode ser escolhida.

As soluções propostas são apoiadas em razões. Há soluções
Diante do conflito entre o certo e o errado, o estudante decide acreditar mais na sua intuição do que na autoridade.

A incerteza é insuportável para alguns estudantes que chegam a abandonar os cursos, ou se comportam de forma alienada.

Estudantes começam a aprender os métodos e critérios da sua 
melhores do que outras, e devem ser analisadas em contexto.
A maior parte do conhecimento é contextual e pode ser julgada qualitativamente. $O$ que é aprendido com outros pode ser integrado a reflexões pessoais.

disciplina e a avaliar as soluções.

6. Pré-engajamento
O conhecimento deixa de ser absoluto.
Estudantes aceitam a responsabilidade do engajamento perante o próprio conhecimento, com base em valores individuais.

A responsabilidade implica em fazer julgamentos.
8. Desafios do engajamento

O relativismo do mundo é uma forma de afirmação da própria identidade.
Os estudantes experimentam as consequências do compromisso e da responsabilidade perante $o$ conhecimento.

\section{Engajamento desenvolvido}

\author{
Escolhas são feitas diante de \\ alternativas legítimas e da dúvida \\ genuína. Epistemologicamente, o \\ sujeito que conhece e aquilo que \\ ele conhece são, agora, \\ inseparáveis.
}

\section{Estudantes entendem que o engajamento é progressivo, mas que se pode retroagir nas posições em relação a diferentes conhecimentos.}

Fonte: adaptado de Perry (1999, $1^{\text {a }}$ edição 1968)

A documentação de William Perry, apesar de numerosa, limitou-se à Universidade de Harvard, portanto a uma amostra de rapazes, de classe média alta americana, nos anos 1960. Essa é uma das fragilidades de se tomar o esquema como referência, mas sua atualização em outros estudos permite considerá-la útil, desde que tomadas as cautelas de contextualização e triangulação. Ficou evidente, no estudo de Perry, que são necessários vários anos para o amadurecimento natural dos estudantes, mas o ensino formal pode sistematizar e organizar esse processo através de tarefas em que não sejam frustrados com desafios impróprios para seu estágio de desenvolvimento. Com base nessa premissa, apresentaremos adiante atividades didáticas realizadas nas disciplinas de Introdução ao Projeto de Produto Industrial (InPi) e Análise de Produtos Industriais (AnPi) ocorridos em curso de Desenho Industrial da UFSM, Universidade Federal de Santa Maria, Rio Grande do Sul.

No período de um ano letivo houve oportunidade de ensinar projetação e análise de produtos para os estudantes do terceiro semestre de ensino regular da UFSM. De acordo com o Projeto Pedagógico do Curso a posição da disciplina na grade curricular, no terceiro semestre, permitia iniciar a preparação dos estudantes em atividade de projeto e análise no segundo ano de sua formação superior em Desenho. Esse momento do curso nos pareceu apropriado para propor as indagações que levassem os estudantes a refletirem sobre seus próprios aprendizados. Um formulário eletrônico com sete perguntas foi respondido pelos estudantes anonimamente. Apresentamos a seguir informações sobre as disciplina, bem como os resultados da sondagem. Instrumentos de coleta de dados e de interpretação se inspiraram na pesquisa de Carmel-Gilfilen e Portillo, que também será muito brevemente explanada. 


\section{O raciocínio projetual pode ser aprendido e refinado, com suporte instrucional}

"Introdução ao Projeto de Produto Industrial" é disciplina no terceiro semestre de curso de Desenho Industrial, com carga horária de 60h/aula. Possui como Objetivos: Compreender as características de Metodologias Específicas em Desenho Industrial e posicionar o projeto no contexto do Planejamento de Produto Industrial. Estabelecer as características de produtos com base nos Fatores Projetuais. Fundamentar suas decisões projetuais com base na expressão gráficovisual das ideias. O Programa é dividido em três unidades, Primeira Unidade: Procedimentos em Desenho de Projeto: (i) Ordem e Arranjo no desenho de projetos; (ii) Ferramentas para projetar desenhos; (iii) A pesquisa no projeto de produtos. A Segunda Unidade: Projeto em Desenho Industrial: (i) Planejamento de Produtos Industriais: uma proposta de ensino; (ii) Metodologia Específica para projetos em Desenho Industrial; (iii) Processo Criativo e Logogramas; (iv) Métodos Particulares de Desenho de Produtos Industriais; (v) Raciocínio Projetual e geração de ideias; (vi) Ética Profissional no projeto de Desenho Industrial. A Terceira Unidade: Apresentação de Projetos: (i) Projeto de produtos industriais como Portfólio; (ii) Apresentação dígito-virtual de projetos; (iii) Mocapes para Pensar, Testar e Apresentar ideias de produtos industriais.

"Análise de Produtos Industriais" é disciplina no terceiro semestre de curso, com carga horária de 60h/aula. Possui como Objetivos: Estudar a dimensão estético-formal, técnicofuncional e lógico-informacional de produtos industriais por meio de técnicas de análise, buscando compreensão da estrutura das suas partes, composição de componentes e ordem e arranjo de seus elementos, por meio da teoria e prática. O Programa é dividido em seis unidades, Primeira Unidade: Bases Conceituais da Análise de Produtos Industriais: (i) Processo de comunicação: emissor/receptor; (ii) Mensagens gráfico-verbais, gráfico-visuais e glífico-táteis; (iii) Relação entre forma, função e significado. A Segunda Unidade: Essências Gerais para Projetação: (i) Malhas gráficas; (ii) Metódicas, Metodologias e Métodos de Projeto; (iii) Taxonomia de Produtos Industriais; (iv) Pesquisa em Desenho Industrial. A Terceira Unidade: Essências Específicas para Desenho Industrial: (i) Criatividade; (ii) Cor; (iii) Estética Industrial; (iv) Crítica e Questionamentos. A Quarta Unidade: Essências Particulares para Desenho de Produtos: (i) Leiaute; (ii) Tipografia; (iii) Imagem; (iv) Identidade; (v) Planejamento e Desenvolvimento; (vi) Ordem e Complexidade; (vii) Funções de Produto; (viii) Ciclo de Vida. A Quinta Unidade: Técnicas de Análise de Produtos Industriais: (i) Técnica de Análise Linguística Denotativa/Conotativa; (ii) Técnica de Análise Linguística Diacrônica/Sincrônica; (iii) Técnica de Análise Linguística Paradigma/Sintagma; (iv) Técnica de Análise Desenhística Estrutural; (v) Técnica de Análise Desenhística Funcional; (vi) Técnica de Análise Desenhística Morfológica. A Sexta Unidade: Síntese de Dados para Projetos: (i) Construção do sistema: dados, informação, conhecimento e sabedoria; (ii) Vantagem competitiva em Desenho Industrial; (iii) Relatório final de Análise de Produtos Industriais.

As disciplinas são ministradas na terça e quinta-feira, respectivamente, e de maneira integrada, isto é, as atividades de análise são contextualizadas no processo projetual e os estudantes trabalham de forma integrada e construtiva. O Objetivo Específico, Educacional, desta proposta didática é APRIMORAR o ensino de Introdução ao Projeto de Produto Industrial e Análise de Produtos Industriais, procurando relacionar Etapas, Fases, Procedimentos da prática projetual do designer contemporâneo com Essências, Técnicas e Sínteses das análises de produtos industriais. Os Objetivos Gerais, Instrucionais, são (i) PROJETAR produtos de baixa complexidade industrial, com base em Etapas, Fases, Procedimentos e Técnicas presentes no programa da 
disciplina; (ii) ANALISAR produtos de baixa complexidade tecnológica, com base na pesquisa das Essências e nas Técnicas Linguísticas e Desenhísticas; e (iii) EXPERIMENTAR em sala de aula novas didáticas que reordenem a Educação Projetual e o Ensino de Desenho industrial (Quadro 2).

Quadro 2 - Abordagem Teórica da disciplina AnPi

\begin{tabular}{ll}
\hline $\begin{array}{l}\text { 1. Essências Gerais } \\
\text { para Projetação }\end{array}$ & $\begin{array}{l}\text { Malhas Gráficas } \\
\text { Método de Projeto } \\
\text { Taxonomia de Produtos } \\
\text { Pesquisa }\end{array}$ \\
\hline $\begin{array}{l}\text { 2. Essências Específicas } \\
\text { para Desenho Industrial }\end{array}$ & Criatividade \\
& Cor \\
& Estética Industrial \\
Crítica e Questionamentos
\end{tabular}

Fonte: Baseado em Smaniotto (2012)

São disciplinas densas, os alunos se queixam da quantidade de tarefas, mas todo o esforço se justifica pelo estabelecimento de uma cultura de PROJETAR ESTUDANDO, ou seja, de os estudantes construírem conhecimento projetual a partir de estudo sistemático realizado no projeto (Quadro 3).

Quadro 3 - Visão geral dos trabalhos resultados das disciplinas.

\begin{tabular}{llll}
\hline $\mathbf{2 0 1 6}$ & $\mathbf{2 0 1 7}$ & \\
\hline InPi-31 alunos & AnPi-43 alunos & InPi-31 alunos & AnPi - 44 alunos \\
\hline $\begin{array}{l}\text { Estudos de Pranchas de } \\
\text { Projeto }\end{array}$ & $\begin{array}{l}\text { Redações Compilatórias } \\
\text { Essências }\end{array}$ & $\begin{array}{l}\text { Estudos de Pranchas de } \\
\text { Projeto }\end{array}$ & $\begin{array}{l}\text { Redações Compilatórias } \\
\text { Essências }\end{array}$ \\
\hline $\begin{array}{l}\text { Desenho de Projeto de } \\
\text { Produto Industrial: } \\
\text { Artefato e Comunicação }\end{array}$ & $\begin{array}{l}\text { Preparação do Projeto - } \\
\text { Análises de Produtos }\end{array}$ & $\begin{array}{l}\text { Desenho de Projeto de } \\
\text { Produto Industrial: }\end{array}$ & $\begin{array}{l}\text { Preparação do Projeto - } \\
\text { Análises de Produtos } \\
\text { Industriais }\end{array}$ \\
\hline Apresentação de Projeto & $\begin{array}{l}\text { Relatório de Análise de } \\
\text { Produtos Industriais }\end{array}$ & Apresentação de Projeto & $\begin{array}{l}\text { Relatório de Análise de } \\
\text { Produtos Industriais }\end{array}$
\end{tabular}

Fonte: Elaborado pelo autor, com base no trabalho da disciplina 
Esta não é a única maneira de realizar tal abordagem mas foi escolhida por (i) fundamentar e focalizar o conhecimento teórico-conceitual e prático-metodológico no Desenho Industrial; (ii) estudar as Essências do Desenho Industrial vinculadas ao fazer projetual; e (iii) integrar as duas disciplinas (InPi + AnPi) de forma a complementar conhecimentos, estimular o estudo e implementar a projetação como modo de trabalho a ser seguindo nos futuros Laboratórios de Projeto do Curso e também dos escritórios Profissionais. $\mathrm{O}$ trabalho foi dividido entre os membros de cada equipe de projeto, sendo o professor orientador responsável pela organização das tarefas, exposição de conteúdos nas aulas e orientação das equipes.

As turmas numerosas exigiram do docente um grande esforço de planejamento e estabelecimento de rotinas, o que, no entanto, permitiu a replicação de exercícios e a possibilidade de observação de padrões de aprendizado, corroborando nossa percepção de que o raciocínio projetual e criativo pode ser aprendido e refinado a partir de experiências sistemáticas de aprendizagem que se equilibrem entre desafios intelecto-criativos e suporte instrucional. Essa experiência didática suscitou o interesse em utilizar um instrumento de coleta de impressões dos estudantes sobre o processo de estudo, numa tentativa de capturarmos indicações de mudança de atitude de engajamento perante o conhecimento.

Esta estrutura conceitual foi utilizada de maneira a dar ênfase às Técnicas de Análise de Produtos Industriais por meio da "Essência Pesquisa: Análises Linguísticas e Desenhísticas", onde os estudantes relacionaram as análises de produto Linguísticas e Desenhísticas dentro da etapa de Preparação do Projeto, com o objetivo de gerar sínteses de informações e diagnósticos que permitam a realização da Apresentação do Desenho. A seguir descreve-se as particularidades das atividades desenvolvidas.

\subsection{Atividade 1 de InPi - Exercício de composição de pranchas de projeto}

Exercício de composição de Pranchas de Projeto, feito a partir de artigo sobre o tema publicado por Gomes (2005). Solicitou-se aos estudantes (i) papel manteiga; (ii) canetas nanquim de espessura $0,3 \mathrm{~mm} ; 0,6 \mathrm{~mm}$; e $1,2 \mathrm{~mm}$; e (iii) pranchas base de malhas diagramacionais. Os estudantes deveriam realizar esboços de possibilidades de arranjo das pranchas de projeto, levando em consideração os elementos: título, subtítulo, texto, imagens, legendas e identificação. A entrega final do trabalho foi composta de um conjunto de materiais: envelope $A 3$ contendo 5 pranchas com 6 miniaturas; 3, com 4 miniaturas e 3 com tamanho 1:1.

\subsection{Atividade 2 de InPi - Desenho de Projeto de Produto Industrial}

Abordou (i) desenho-de-artefato [glífico-tátil]; e (ii) desenho-de-comunicação [gráfico-visual] de um produto de baixa complexidade tecnológica, respectivamente: Produto Glífico-tátil [Banco / Poltrona / Cadeira de madeira (pinus, MDF) estruturada por encaixes, sem pregos / parafusos]; e Gráfico-visual [Identidade Visual (Símbolo, Logotipo, Padrão Cromático, Padrão Tipográfico); e Cartaz promocional]. A equipe poderia ter até 4 estudantes. $O$ trabalho seguiu, em sua macroestrutura, os procedimentos metodológicos inspirados em Bonsiepe et al. (1984), no Planejamento de Produto Industrial e no Processo Criativo. A entrega final do projeto foi composta de um conjunto de Documentos Projetuais criados durante todo o semestre: Relatório de Projeto (virtual); Pasta do Projeto (pranchas); e Mocapes (Pensar, Testar e Apresentar) e Desenhos Operacionais. 


\section{Artigo Completo}

\subsection{Atividade 3 de $\operatorname{InPi}$ - Apresentação Final de Projeto}

Deu-se por meio de um conjunto de materiais com três partes: (i) Portfólio de Projeto [de Produtos Industriais]: desenvolvimento, à mão, das pranchas em tamanho A3, conforme fases, etapas, procedimentos e técnicas orientadas em sala de aula reunido e entregue em pasta personalizada, de acordo com orientação; (ii) Relatório [Dígito-virtual] de Projeto: Com base na sistemática de apresentação de projetos de Gerardo Rodriguez (1980), desenvolveu-se apresentação do trabalho, de forma a sintetizar o projeto; (iii) Mocapes [para Pensar, Testar e Apresentar] o Produto: durante o desenho do projeto, os estudantes intercalaram a geração de alternativas bidimensionais e tridimensionais, destacando a necessidade de Mocapes para apresentar os produtos fruto do desenho-de-artefato e desenho-de-comunicação.

Figura 1 - Detalhes do trabalho projetual e análise de uma equipe de trabalho até o mocape em escala

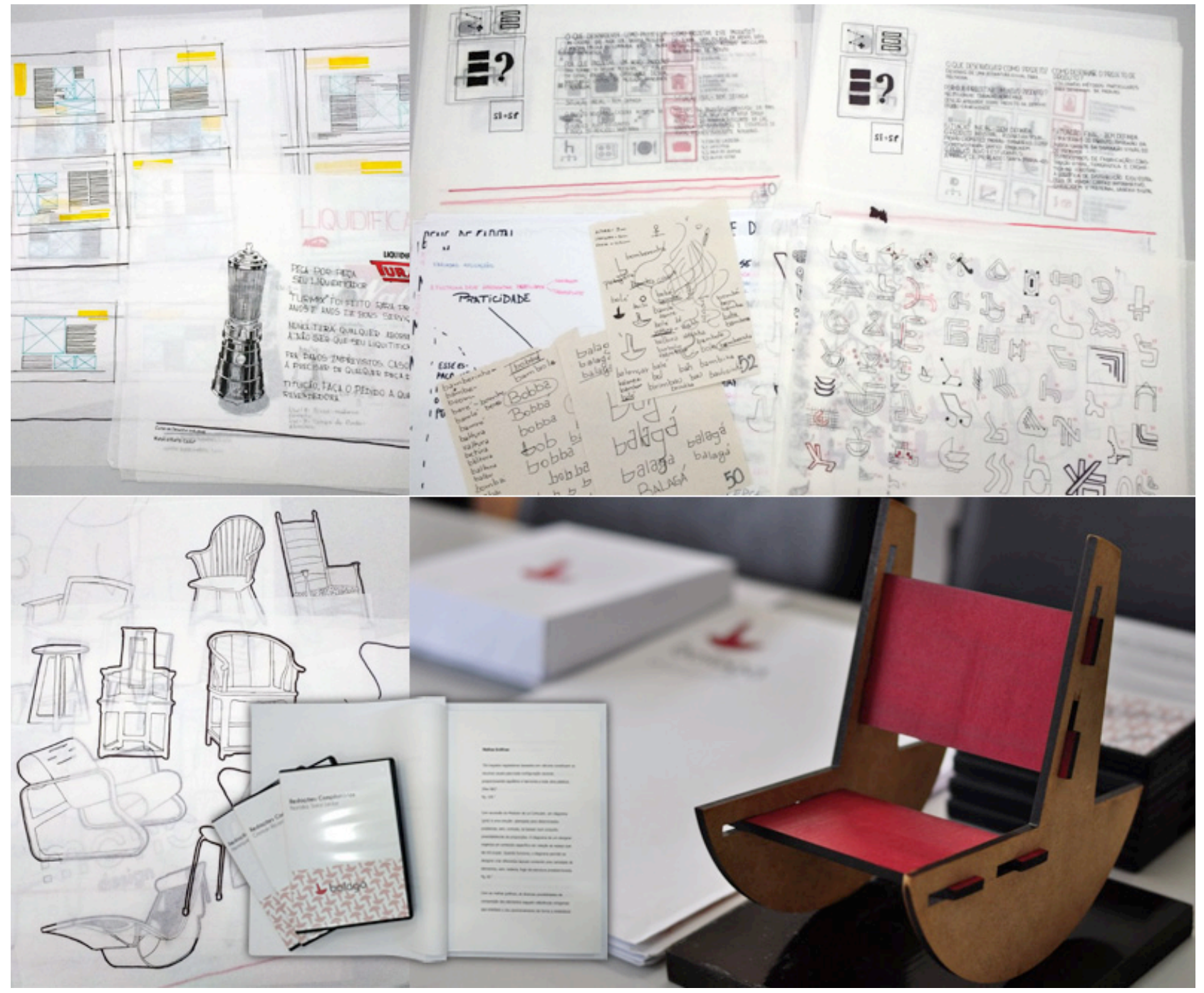

Fonte: acervo dos autores 


\subsection{Atividade 1 de AnPi - Redações Compilatórias (RCs)}

Redação Compilatória para InPi + AnPi. Após a leitura do artigo "Essências para o Desenho Industrial/Design (DiD)" (Smaniotto et al., 2012) os estudantes deveriam iniciar o trabalho de pesquisa e Redação Compilatória das Essências do Desenho Industrial/Design: Malhas Gráficas, Método de Projeto, Taxonomia, Pesquisa, Criatividade, Cor, Estética Industrial, Crítica e Questionamentos, Leiaute, Tipografia, Imagem, Identidade, Planejamento/Desenvolvimento, Ordem e Complexidade, Funções do Produto e Ciclo de Vida. As RCs enriqueceram o debate com informações de fontes confiáveis elevando o nível da conversação entre o professor e os estudantes. Nos encontros destinados aos Colóquios foi estimulada a articulação do conhecimento teórico com a prática profissional e a pesquisa desenhística.

\subsection{Atividade 2 de AnPi - Análises de Produto Industrial}

Realizadas a partir das técnicas de análises Linguísticas (para ampliar o vocabulário verbal e visual dos alunos, e propiciando o aumento da fluência projetual na solução dos problemas) e Desenhísticas (para detalhar estrutura, função e morfologia dos produtos analisados anteriormente pela Linguística, preparando o trabalho e esclarecendo o problema projetual). Sua avaliação deu-se com base nos Documentos Projetuais da Fase de Preparação do Processo Criativo e das pranchas da Pasta do Projeto.

\subsection{Atividade 3 de AnPi - Relatório de Análise}

Teve grande importância na construção de um sistema que organizou dados, informação e conhecimento conferindo sabedoria projetual aos alunos. A avaliação do Relatório de Análises de Produto Industrial foi realizado com base nos resultados obtidos a partir do uso das técnicas analíticas Linguísticas e Desenhísticas. Tratou-se de um documento que apresentasse as análises e foi organizado primando pela ordem, arranjo e ter coerência formal com o documento de Apresentação de Projeto do Produto.

\section{O estudo de Carmel-Gilfilen e Portillo}

Utilizando o modelo de Perry, 32 estudantes de design em inicio de curso e em estágio intermediário foram analisados por Carmel-Gilfilen e Portillo a partir de questões propostas. Suas conclusões empíricas apoiam as posições de Perry e correlacionam desenvolvimento do pensamento com o momento do estudante no curso e desempenho projetual. Novatos, em geral, quando na posição de "dualismo" empregam menos recursos e possuem uma compreensão limitada dos critérios de análise se comparados com os estudantes que se encontram na posição de "multiplicidade". Os "dualistas" conseguem entender os critérios como restrições ou requisitos para alimentar um processo projetual linear. Os estudantes "múltiplos", em estágio intermediário do curso, realizam uma abordagem mais integrada. A habilidade avançada de raciocínio projetual, em última instância é isso: equacionar global e simultaneamente fatores, na maioria das vezes conflitantes. As questões exemplificadas no Quadro 4 e seus modelos interpretativos foram úteis para a construção dos instrumentos da nossa própria pesquisa. 
Quadro 4 - questões formuladas em Carmel-Gilfilen e Portillo

Questão 1: Qual é a sua opinião sobre o trabalho preparatório do projeto, realizado na forma de esboços e anotações sobre o problema projetual?

"Eu faço rabiscos e rascunhos a mão, mas logo que meus conceitos iniciais estão prontos eu passo a trabalhar no computador."

\section{Exemplo de Interpretação}

O estudante não compreende as conexões entre trabalho preparatório e geração da solução projetual. 0 processo projetual é linear.

\begin{abstract}
"Sinto que desenhar diagramas definitivamente ajuda porque isso facilita a visualização do espaço. Os cortes e seções também ajudam."
\end{abstract}

\section{Exemplo de Interpretação}

O estudante nessa posição usa a preparação como um recurso para reduzir a indefinição do problema.

Questão 2: Se você pudesse aconselhar alguém sobre como aprender melhor numa aula de projeto, o que você diria? Descreva o que você acredita ser a chave para projetar.

"Escute o seu professor! Por que mesmo que pense que pode chegar à solução, você não sabe como chegou lá."

\section{Exemplo de Interpretação}

O estudante nessa posição não se sente responsável pelo resultado do seu trabalho.
"Justifique o seu projeto pela pesquisa, ou outra evidência pertinente ao problema."

\section{Exemplo de Interpretação}

O estudante entende que solução projetual não é preferência; deve haver um propósito.

Questão 3: Como você sabe que o seu projeto está bom?

“Meu projeto está bem se eu tirar ' $A$ ' e o professor não tiver muito a dizer."

\section{Exemplo de Interpretação}

O estudante nessa posição acredita que se seguir o que o professor mandar, merece boa nota.
"Só será mesmo possível avaliar quando o produto for utilizado na vida real, mas um projeto bem sucedido é baseado em pesquisa, e soluciona o problema do cliente. A avaliação ocorre ao longo de todo o projeto."

\section{Exemplo de Interpretação}

O estudante nessa posição compreende a importância da crítica nas várias fases do projeto.

Fonte: adaptado de Carmel-Gilfilen e Portillo (2010)

\section{Sondagem com alunos: instrumentos de coleta de dados e de interpretação}

Criamos um formulário eletrônico com a seguinte mensagem para os estudantes: "Esta breve pesquisa é destinada a vocês, ex-alunos das turmas de Introdução ao Projeto e Análise de Produtos. Peço que respondam algumas perguntas com a intenção de verificarmos se algum rumo precisa ser alterado nas disciplinas em andamento. Alguns dos objetivos da disciplina de Introdução ao Projeto eram compreender as características de metodologias específicas em Desenho Industrial e posicionar o projeto no contexto do Planejamento de Produto Industrial assim como fundamentar as suas decisões projetuais com base na expressão gráfica. Assim, gostaria de saber:" (Quadro 5). 
Quadro 5 - Sondagem com alunos da disciplina InPi e AnPi

Questão 1 Qual era o conceito de Criatividade antes de iniciar a disciplina? E depois?

Questão 2 O que você compreende, atualmente, por Criatividade Orientada?

Questão 3 Você já havia relacionado Processo Criativo com Processo Projetual?

\section{Questão 4 Como você define, hoje, Método de Projeto?}

Questão 5 Em que medida os exercícios realizados em Introdução ao Projeto e Análise de Produto ajudaram a administrar o seu tempo, recursos, processos, procedimentos e técnicas durante os Laboratórios?

Questão 6 Ao cursar um dos Laboratórios do curso, após Introdução ao Projeto você acredita que o processo projetual/criativo foi otimizado?

Questão 7 O que você pode dizer, para finalizar, sobre a experiência acadêmica realizada nas disciplinas de Introdução ao Projeto e Análise de Produtos?

Fonte: adaptado de sondagem com alunos das disciplinas InPi e AnPi

Diferentemente do estudo de Carmel-Gilfilen e Portillo, que compara respostas de estudantes iniciantes e intermediários no curso, aqui observamos as reflexões de estudantes sobre seu próprio desenvolvimento após uma disciplina.

Quadro 6 - Respostas à questão 1 em sondagem com alunos da disciplina InPi e AnPi.

Questão 1 Qual era o conceito de Criatividade antes de iniciar a disciplina. E depois?

Antes parecia ser algo mágico e herdado mas depois vi que é a relação de aprendizados obtidos ao longo da vida através das sensações.

Antes era ter várias ideias inovadoras a partir de relações entre situações já vividas. Depois virou algo a ser treinado, como qualquer outra coisa na vida, algo que deve ser constantemente exercitado através de referências, leitura, métodos e conceitos.

Antes considerava criatividade como uma característica específica de algumas pessoas, como se fosse um dom. Depois entendi que o ato de criar é inerente ao ser humano e a criatividade pode ser estimulada/treinada e que possui algumas ramificações e categorias.

Criatividade parecia algo sombrio e misterioso que funcionava de formas imprevisíveis. Porém, ao cursar a disciplina, Ficou claro que criatividade nada mais é do que um processo de iterações a fim de, através de pesquisa e exploração de alternativas, chegar a melhor resolução possível para dado problema. Em outras palavras, criatividade pode e deve ser exercitada através de algum método a fim de chegar em soluções melhores.

Inicialmente a visão de criatividade se baseava em algo livre e espontâneo, algo que em algum momento eu encontraria a resposta com ou sem uma referência, após aplicar praticamente métodos para extrair a criatividade, o conceito passou a ser mais voltado ao lado de aprender a utilizar a ferramenta para conseguir aquele resultado desejado. Várias formas apresentadas na disciplina se tornaram uma rotina para outros projetos, melhorando a visão do todo de um projeto, ilustração, etc.

O meu conceito de criatividade antes da disciplina estava alinhado com o senso comum, tendo a criatividade como 
uma espécie de dom, ou fase que se manifestava de maneira quase espontânea. Após a disciplina pude ver um pouco além, sem extinguir por completo meu conceito anterior, onde passei a ver a criatividade, também, como uma ferramenta que pode ser estimulada, moldada e aperfeiçoada conforme as necessidades projetuais.

Tinha criatividade como algo que agente desenvolve com o tempo, ou até algo mais intuitivo. Após a disciplina passei a enxergar a criatividade como algo a ser exercitado e explorado a partir de ferramentas, tanto oriundas de metodologias já existentes, quanto a descobrir, a partir delas, um método particular para desenvolve-la.

Talento, intuição, inteligência, possibilidade de ver com outros olhos ou de uma perspectiva diferente, fazer diferente, criar. Algo subjetivo e próprio das pessoas. Não pensava sobre o exercício da criatividade muito menos em processo criativo.

Fonte: adaptado de sondagem com alunos das disciplinas InPi e AnPi

Pode-se observar, nas respostas, uma transição da percepção de uma verdade exterior ("algo mágico e herdado"), para uma responsabilidade com o engajamento progressivo em relação ao conhecimento ("aprendizados obtidos ao longo da vida"; "algo que deve ser constantemente exercitado através de referências, leitura, métodos e conceitos").

À medida que os estudantes aceitam aprender os métodos e critérios da sua disciplina, sentem-se capazes de fazer julgamentos com responsabilidade ("através de pesquisa e exploração de alternativas, chegar a melhor resolução possível para dado problema”).

Quadro 7 - Respostas à questão 7 em sondagem com alunos da disciplina InPi e AnPi..

Questão 70 que você pode dizer, para finalizar, sobre a experiência acadêmica realizada nas disciplinas de Introdução ao Projeto e Análise de Produtos?

Foi muito instrutiva e me mostrou uma forma diferente e muito prática de como formular conceitos para projetos.

Demandou bastante tempo para ser executadas com qualidade, porém o ganho de conhecimento sobre projeto é imenso. Com certeza é umas das cadeiras mais importantes, que irão guiar quase todos os projetos até o final do curso, ajudando a melhorar a qualidade e desempenho dos mesmos.

Todo o cansaço vale MUITO a pena, já que os ganhos em conhecimento são enormes e o trabalho que desenvolvemos nas disciplinas é fantástico e gratificante. Para mim são duas das melhores cadeiras que o curso oferece.

Não foi um processo fácil. Foi uma disciplina puxada, exaustiva e houve bastante turbulência no seu decorrer. Contudo, foi provavelmente uma das disciplinas (se não a disciplina) mais recompensadora do curso. Foi gerado muito conhecimento e aprendizado bem como os resultados finais ficaram satisfatórios em sua maioria. Durante a disciplina pode ser até complicado para alguns reconhecerem o seu valor, mas tenho certeza que após ela todo mundo cresceu bastante e tirou várias lições importantes.

Realmente é estressante para os estudantes do terceiro semestre criarem a noção necessária do quão útil o conhecimento de projeto pode ser, geralmente só perceberão a importância posteriormente, afinal o projeto é cansativo e precisa de muito foco e trabalho para ser finalizado. Entretanto, é um experiência que causa uma transição dentro do curso, reconhecida pelos próprios estudantes. O terceiro semestre é uma representação breve de como iremos trabalhar futuramente, uma introdução literal ao mundo do design e projeto, sem dúvidas é algo que todos precisam passar até para criar essa maior consciência sobre todas as dificuldades futuras e sobre como não ficar empacado no futuro.

A disciplina teve grande impacto positivo sobre a minha percepção de Projeto, no entanto, acho relevante 
ressaltar que esse contato tenha acontecido de uma forma mais súbita, em relação aos meus colegas, já que na época a minha falta de maturidade acadêmica, e de forma geral, influenciaram diretamente nas experiências durante e após as disciplinas.

Acho que foi um exercício e um aprendizado projetual com alto valor para meu desenvolvimento, tanto profissional quanto acadêmico. Principalmente na questão de análise de produtos, o que considero fundamental para o desenvolvimento de novos. Assim como os requisitos de projetos terem sido inspiradores para a criação do produto final proposto. Um abraço.

Pouco tempo para aprender tantas coisas importantes. Foi muito confuso em alguns momentos, mas gratificante no final. Me fez falta na parte de criação de significado do produto, talvez uma aula de análise de conceito, semântica ou função simbólica seja muito interessante, a final, especificar funções é relativamente fácil e flexivelmente corrigível, entretanto, produtos com conceitos fracos tendem a ser pobres e pouco atrativos.

Fonte: adaptado de Sondagem com alunos da disciplina InPI e AnPi

É importante destacar que as atitudes dos estudantes se alteraram no decorrer de um semestre. De alunos apreensivos no início, para alunos felizes com seus projetos, produtos e produção, no final, houve uma mudança significativa. $O$ aumento da segurança deu-se com o cumprimento das fases, procedimentos e técnicas. A cada apresentação a melhora na autoestima foi sendo percebida e, mais importante, eles se deram conta que o seu trabalho era o mecanismo mais importante de autovalorização. Cada grupo de trabalho soube equilibrar os momentos de tensão e incerteza com mais trabalho e, mais importante, com mais desenhos. $O$ ponto fundamental de todos os projetos foi a impressionante produção de Documentos Projetuais classificados em cada um dos grandes estágios [Preparação do Projeto, Apresentação do Desenho, Realização do Produto] do trabalho. Em todos os trabalhos, o pedido era que houvesse uma proposta de produto, quer dizer, um grupo de trabalho de quatro pessoas, apresentaria uma proposta. Porém, dois grupos decidiram seguir e apresentar três propostas diferentes, e finalizar o projeto de todas, seguindo até os Desenhos Operacionais. Este é um dos fatos do envolvimento afetivo dos estudantes com as ideias geradas. A necessidade de confecção de mocapes também é outro ponto a ser destacado pois eles eram feitos em paralelo com a geração bidimensionais de ideias. Convém destacar o potencial de atenção diferenciada que professor pode dispensar a grupos com mais dificuldade, uma vez que todos possuem o mesmo roteiro. Com isso, o trabalho pode ser nivelado com o passar do semestre, chegando ao final com todos com resultados muito aproximados, do ponto de vista do processo projetual. Para finalizar, a divisão de tarefas de Introdução ao Projeto e Análise de Produto dar-se em dois dias diferentes, permitiu trabalhar Análises e Geração em paralelo e de maneira quase simultânea, tornando a Avaliação e a Produção conectadas e iterativas. Até o momento, esta proposta tem se mostrado produtiva, com resultados de impacto.

\section{Uma breve discussão sobre a relevância do tema para a área de conhecimento}

Diferentemente dos estágios de desenvolvimento de uma criança, que, em situações de normalidade, são consecutivos e irreversíveis, as posições no esquema de Perry são alternáveis, dependendo do contexto. Cada um de nós pode se encontrar em "dualismo" diante do desafio do aprendizado de algo novo, desafiador, independentemente de já termos alcançado a posição de 
"engajamento desenvolvido" em nossos campos de atuação e plena competência. Se quisermos aprender, pela primeira vez, a tocar um instrumento musical, assumiremos a posição de polaridade "certo x errado" esperando que a "autoridade" —o professor de violino, por exemplo - nos dê as soluções para nossos problemas de aprendizado. Agiremos tal como um calouro em curso de graduação, ou aluno ingressando em disciplina com um professor novo.

$\mathrm{Na}$ disciplina InPi, o docente pôde oferecer aos estudantes tarefas planejadas, partindo de um ordenamento rigoroso na "Atividade 1: Exercício de composição de pranchas de projeto". Solicitações muito explícitas como tipo de papel, especificação da espessura das canetas, uso de base de malhas diagramacionais, estão consonantes com a posição de dualidade básica. $O$ suporte instrucional visa estimular o desenvolvimento intelectual, potencializando o amadurecimento natural, por isso, a "Atividade 2: Desenho de Projeto de Produto Industrial" previa a apresentação de documentos produzidos no decorrer do semestre, composto de arquivos digitais, pranchas, mocapes diversos e desenhos operacionais. Para gerar o conjunto de documentos, os estudantes precisaram aprender os métodos e critérios de disciplina e a avaliar soluções. Mesmo enfrentando incertezas, conflitos e descrédito no processo, chegaram às soluções apoiadas em razões, analisadas em seus contextos. Na "Atividade 3: Apresentação Final de Projeto" os alunos intercalaram a geração de alternativas bidimensionais e tridimensionais, gerenciando escolhas e dúvidas genuínas.

O mesmo processo ocorreu na disciplina AnPi, desenvolvida também em três atividades de cunho analítico, portanto exigente do ponto de vista reflexivo. Como mencionado por um dos respondentes, "não foi um processo fácil. Foi uma disciplina puxada, exaustiva e houve bastante turbulência no seu decorrer. ... Durante a disciplina pode ser até complicado para alguns reconhecerem o seu valor, mas tenho certeza que após ela todo mundo cresceu bastante e tirou várias lições importantes". Não é incomum que o estudante, ao perceber a diversidade de caminhos, rebele-se contra o desconforto da incerteza e atribua a confusão a "autoridades mal preparadas" ou o sofrimento sentido a um mero capricho delas. Além da rebeldia, William Perry identificou circunstâncias de demora, desvio e recuo no desenvolvimento de estudantes (Perry, 1999, p. 11). Ele denominou "temporização" a demora em superar uma posição, quando o estudante hesita em dar o próximo passo no sentido de se engajar no aprendizado. "Escapismo" é a exploração, pelo estudante, da oportunidade de imparcialidade oferecida pelas estruturas de pensamento das Posições 4 e 5 . Ele se nega a assumir responsabilidade, comportando-se com alienação passiva e oportunista. "Recolhimento" é a permanência no dualismo das Posições 2 e 3. Não é difícil reconhecermos esses comportamentos em sala de aula.

As ressalvas à teoria de Perry são admitidas no seu próprio relato e entre analistas. Apesar disso, há relevância no conhecimento dessas ideias para se compreender melhor o desenvolvimento das trajetórias de estudantes de design. Acreditamos que alunos e docentes, tomando ciência de teses sobre desenvolvimento acadêmico e profissional, podem explorar as conexões com o raciocínio projetual e assim assumirem responsabilidade recíproca no processo de ensino-aprendizagem em cursos de Desenho Industrial/Design. 


\section{Referências}

CARMEL-GILFILEN, C.; PORTILLO, M. Developmental trajectories in design thinking: an examination of criteria. Design Studies, Volume 31, n. 1, p. 74-91, 2010.

COX, M. Desenho da Criança. São Paulo: Martins Fontes, 2001.

CROSS, N. Expertise in design: an overview. Design Studies, Volume 25, n.o 5, p. 427-441, 2004.

DAVIS C.J. et al. Expertise as a Mediating Factor in Conceptual Modeling. In: Davis F., Riedl R., vom Brocke J., Léger PM., Randolph A. (eds) Information Systems and Neuroscience. Lecture Notes in Information Systems and Organisation, vol 25. Springer, p. 85-92, 2018.

FREEMAN, N. Strategies of Representation in Young Children: analysis of spatial skills and drawing process. London: Academic Press, 1980.

GÖKER, M. H. The effects of experience during design problem solving. Design Studies, Volume 18, n. 4, p. 405-426, 1997.

GOMES, L.; MEDEIROS, L. Retículas, Grelhas e Malhas: Noções Fundamentais e Aplicações. In: VI Congresso Internacional de Engenharia Gráfica nas Artes e no Desenho e $17^{\circ}$ Simpósio Nacional de Geometria Descritiva e Desenho Técnico, Recife, 2005.

GOLDSCHMIDT, G. Contents and structure in design reasoning. Design issues, Volume 14, n. 4, p. 85-100, 1998.

$\mathrm{HO}, \mathrm{C}$. Some phenomena of problem decomposition strategy for design thinking: differences between novices and experts. Design Studies, Volume 22, n. 1, p. 27-45, 2001.

KAVAKLI M., GERO J.S. Strategic knowledge differences between an expert and a novice designer. In: Lindemann U. (eds) Human Behaviour in Design. Springer, Berlin, Heidelberg, p. 42-52, 2003.

KELLOG, R. What children scribble and why. Palo Alto, California: National Press, 1959.

LOWENFELD, V., BRITTAIN, L. Desenvolvimento da capacidade criadora. São Paulo: Mestre Jou, 1977.

LUQUET, G. El Dibujo Infantil. Barcelona: Editorial Médica y Técnica, 1981.

MARCHAND, H. Desenvolvimento intelectual e ético em estudantes do ensino superior - implicações pedagógica. Sísifo. Revista de Ciências da Educação n.o 7, p. 9-18, 2008.

MEDEIROS, L. O desenho como suporte cognitivo nas etapas preliminares do projeto. Tese de Doutorado, Rio de Janeiro: COPPE/UFRJ, 2002.

MEDEIROS, L.; NAVEIRO, R. Reflexões Metodológicas sobre o Ensino de Projeto de Produto. In: Pereira Pinto, Danilo; Nascimento, Jorge Luiz (Org.) Educação em Engenharia: Metodologia, São Paulo: Mackenzie, p. 177-197, 2002.

PERRY, W. G. Forms of Ethical and Intellectual Development in the College Years, a Scheme. San Francisco: John Wiley, 1999. (1 $1^{\mathrm{a}}$. ed 1968).

PILLAR, A. Desenho e construção de conhecimento na criança. Porto Alegre: Artes Médicas, 1996.

RODRIGUEZ, G. M. Manual de Diseño Industrial, Curso Básico. Mexico: Gustavo Gili, 1980.

ROWE, P. Design thinking. Cambridge, Massachusetts: MIT Press, 1987.

SMANIOTTO, M.; BROD JR, M.; MEDEIROS, L.; GOMES, L. Essências para o Desenho Industrial/Design (DiD). In: 10으 Congresso Brasileiro de Pesquisa e Desenvolvimento em Design, São Luís: UFMA. 2012.

STONES, C.; CASSIDY, T. Comparing synthesis strategies of novice graphic designers using digital and traditional design tools. Design Studies, Volume 28, n.o 1, p. 59-72, 2007. 